\title{
Evaluating Online Shopping Service Quality-SERVEGAL in Taiwan Tourism Industry
}

\author{
Meiling Wong \\ Department of Industrial Engineering and Management, National Chinyi University of Technology, Taichung \\ Email: $\underline{\text { mlwong001@gmail.com, mlwong@mcut.edu.tw }}$
}

Received July 2014

\begin{abstract}
While SERVQUAL is the most extensively used measurements of service quality among industries nowadays and its five-dimension measured factors are investigated with respect to the customers' reaction, E-SERVQUAL thus is developed amid traditional service industries to cope with the internet markets. Both two models use measured data based upon after purchased instead of prepurchased which is considered as the main concern for service quality. Taking Magal's instrument into account, which indicates three dimensions that possess the function of customers' comments, customers' demand and service planning to measure the service quality, we propose the SERVEGAL model to include customers' recognition on service quality pre-purchasing. And a case study in tourism industry is applied to verify our proposal. The result of this study shows that SERVEGAL is not merely a service planning provider, but also a tool to accommodate with the customers' expectation for service quality.
\end{abstract}

\section{Keywords}

Service Quality, SERVQUAL, E-SERVQUAL, Magal, Fuzzy Analytic Hierarchy Process (FAHP)

\section{Introduction}

In the field of marketing, the construct of perceived value has been identified as one of the most important measures for gaining competitive edge [1], and has been argued to be the most important indicator of repurchase intentions [2]. It is believed leisure/tourism providers could benefit from refined measures of the construct of perceived value. Valid and reliable measures of perceived value would allow for comparison of value between leisure/tourism programs, and would allow individual leisure/tourism providers the ability to identify the dimensions of perceived value in which they perform well or poor [3].

A fundamental base for the conceptualization of perceived value of a service was developed by Zeithaml [3], whose research utilized focus groups and in-depth consumer interviews to explore the relationships between consumers' perceptions of price, quality and value. Perceived value has been defined as "the consumer's overall assessment of the utility of a product based on perceptions of what is received and what is given” [3]. And is 
identified into four diverse meanings of value: (1) value is low price, (2) value is whatever one wants in a product, (3) value is the quality that the consumer receives for the price paid, and (4) value is what the consumer gets for what they give.

While repurchase intentions and consumer loyalty are often predicted solely by measures of consumer satisfaction, and/or service quality [4] [5], Imrie et al. [6] argued that the fundamental role that culture and/or personal values perform through informing consumer evaluation and choice behavior was not considered in the SERVQUAL model [7] when they conducted a field research within Taiwan to ascertain whether the dominant service quality model holds in the "foreign" environment [6]. In their findings, three major themes of sincerity; generosity; and courtesy/politeness were grouped under an umbrella dimension to reflect the supposed impact of Confusion values upon the choice of evaluative criteria, and a richer conceptualization was required to capture issues relating to the central role of personal relationships within the service encounter. The results of their research indicated that not only do cultural values influence the hierarchy of service quality dimensions, but also that the SERVQUAL conceptual model does not capture the breadth of criteria utilized by Taiwan consumers.

Chinese culture provides a tightly knitted social framework in which individuals are protected by one another. It projects a preference for cooperation, group decision-making, and relationships. Thus, the importance of social network lies in their emphasis on collectivism and group harmony [8]. The Chinese strive to keep relationships among guanxi members stable and harmonious since guanxi is the basis on which they exchange a lifetime of favors, resources, and business leverage [9]. And for each specific relationship, people in China reconcile through interpersonal accommodation and negotiation [6] [10]. Therefore doing business in China is literally an art of dealing with the interpersonal relationships [11]-[15].

\section{Guanxi and SERVQUAL}

Chinese are born with guanxi and socially linked to his guanxi network. Guanxi defines one's place in the social structure and provides security, trust and a prescribed role reciprocally with others. Harmonious guanxi (interpersonal relationship) for the Chinese is 'expected' as well as required not only by individuals but also by the whole society, either for strong or weak ties of guanxi which is mostly predetermined by the 'role' accordingly. Maintaining good guanxi thus refers to the delicate art of building and nurturing such ties that is a hybrid of affection and benefit in business. Business with the Chinese thus is considered basically the issue in dealing with guanxi.

Parasuraman et al., [1] [7] attempted to define the dimensions of service quality. A ten dimensional model was later simplified into five major dimensions, namely reliability, responsiveness, assurance, tangibles and empathy. Reliability refers to the ability to perform the service promised. Responsiveness concerns the readiness and willingness in providing the services. Assurance involves the politeness and courtesy in delivering the services and the believability and trustworthiness conveyed to customers. Empathy is defined as the understanding of customers' individual needs and specific requirements. Finally, tangibles include the physical evidence of the service such as facilities equipments and personnel. While customers can judge the quality of manufacturing goods in terms of functions and standards they find it difficult to measure service quality because they have to assess not only the outcome of the service, but more importantly the process of the delivery of that service [16].

It was proposed E-Service Quality (E-SQ) to evaluate the online service quality by the means-end method with the eleven dimensions: access, ease of navigation, efficiency, flexibility, reliability, personalization, security privacy, responsiveness, assurance/trust, site aesthetics, and price knowledge [17]. And then by defining the service quality as "the level of efficiency and effectiveness of online shopping for goods or services" revised it into seven dimensions as efficiency, reliability, fulfillment, privacy, responsiveness and compensation. In last couple of decades online purchase and travel itinerary customization have been the main trend of marketing in leisure/tourism. Although two way interaction online programs are provided to collect and fulfill customer's requests, it seems virtual transaction is making it harder to concretize and further evaluate the service quality in international business considering the cultural difference. The traditional Information System (IS) was not quite adequate for online tourism since it is lack of in time Q \& A with close two-way interaction which can provide information of customers' requests for better service prepared and preplanned ahead of time. Magal [18] thus is designed with three dimensions of Quality of Information Center Service, Degree of User Self-Sufficiency, and Quality of User-Developed Applications that evaluates the Service Quality with the forecasting function. It is believed with Magal [19], the in-time information is provided by the two-way interaction between service providers and receivers for $\mathrm{Q} \& \mathrm{~A}$ and therefore upgrades the service quality. 


\section{SERVEGAL}

SERVEQUAL is to evaluate the service quality after service which is not as efficient as what is supposed to be done prior to the purchase. Combining the SERVEQUAL and Magal, this study proposes SERVEGAL to overcome the lag info collected based upon post sale of SERVEQUAL, also takes cultural factor into account to evaluate the online shopping service quality in Taiwanese tourism industry.

To form up the SERVEGAL, we add in an extra dimension to supplement the forecasting function for SERVEQUAL. This dimension is designed with 2 to 3 online questions that are based upon their perceived value which in fact comes from their cultural aspect (questionnaire provided upon request). And the answers of customer's demands are collected as the before sale information that can be considered for his/her customized itinerary (upon request).

Fuzzy Analytic Hierarchy Process (FAHP) is applied to verify SERVEGAL in this study for the intangible and psychological characteristics of the service quality. Four effective complete questionnaires out of six senior managers of different travel agents interviewed for their expert opinions with questionnaire designed according to the above discussion are collected, and the weights of all dimensions are analyzed with paired comparison matrixes for its consistency and the geometric average is calculated for the overall Fuzzy paired comparison matrixes. In order to defuzzification, we need to find out the best non-fuzzy performance value (BNP). The BNP of the fuzzy Ri can be calculated with the equation and the BNPs can be weighted (detailed upon request).

Accordingly the weighted ratio of the dimensions that evaluate the Service Quality in the above table shows the forecasting is the most significant one in Taiwan tourism industry.

\section{Conclusion and Perspectives}

SERVEQUAL with five dimensions evaluates service quality with post sale data collected based upon customers' satisfaction, which cannot provide the service quality that matches customer's expectation at present transaction. In tourism online shopping, in order to minimize the gap of the perceived service quality between the service provider and receiver, the customer's demand of travel needed to collected and considered into customization before purchase. This study proposes SERVEGAL that combines SERVEQUAL and the forecasting dimension of MAGAL not just evaluates the service quality prior to transaction but also provides the customer's expectation for the service provider to consider into the delivery of the service. Applying FAHP, the SERVEGAL is testified and result shows that the added dimension of forecast is the most significant factor among all others, with a highest weighted ratio of 0.4327 which tells that Taiwanese customers care for interaction and idea exchange the most. Secondary is the empathy with a weighted ratio of 0.2295 which shows it is also important for Taiwanese customers to feel their demands are cared.

Taiwan is a society of Chinese social network. People are linked with guanxi based upon Confucianism philosophy, with which sets up the social norm for interpersonal relationships. In order for the society to stay in harmony, everyone is expected to play his/her adequate role accordingly with the social norm. So it is logical to have the result with FAHP to prove that guanxi and its mechanism is the key in Chinese market. With SERVEGAL, service providers (travel agent in this case) have the customer's expectation collected as the forecasting data to improve their service quality before transaction. And this prepurchase online interaction also reinforces the customer relationship for the better mutual understanding.

For future perspective research, the following subjects are suggested:

1) Online shopping is growing and becoming inevitable for traditional industry to join. An online marketing strategy is urgently needed.

2) The online shopping websites need to be upgraded to provide a more effective two-way interaction between good/service providers and receivers.

SERVEGAL and others alike enables a two-way interaction prior to transaction can be used as a well-established platform for maintaining and reinforcing customer relationship. Its relevant software is expected to developed soon.

\section{References}

[1] Parasuraman, A., Berry, L.L. and Zeithaml, V.A. (1991) Refinement and Reassessment of the SERQUAL Scale. Journal of Retailing, 67, 420-450. 
[2] Parasuraman, A. and Grewal, D. (2000) The Impact of Technology on the Quality-Value-Loyalty Chain: A Research Agenda. Journal of Academy of Marketing Science, 28, 168-179. http://dx.doi.org/10.1177/0092070300281015

[3] Zeithaml, V.A. (1988) Consumer Perceptions of Price, Quality and Value: A Means-End Model and Synthesis of Evidence. Journal of Marketing, 52, 2-22. http://dx.doi.org/10.2307/1251446

[4] Zeithaml, V.A. (1988) Consumer Perceptions of Price, Quality and Value: A Means-End Model and Synthesis of Evidence. Journal of Marketing, 52, 2-22. http://dx.doi.org/10.2307/1251446

[5] Petrick, J.F. (2002) Development of a Multi-Dimensional Scale for Measuring the Perceived Value of a Service. Journal of Leisure Research, 34, 119-134.

[6] Imrie, B.C., Cadogan, J.W. and McNaughton, R. (2002) The Service Quality Construct on a Global Stage. Managing Service Quality, 12, 10-18. http://dx.doi.org/10.1108/09604520210415353

[7] Parasuraman, A., Zeithaml, V.A. and Berry, L.L. (1988) SERVQUAL: A Multiple-Item Scale for Measuring Consumer Perceptions of Service Quality. Journal of Marketing, 64, 12-40.

[8] Kelly, R.E. (2011) A “Confucian Long Peace” in Pre-Western East Asia. European Journal of International Relations, 18, 407-430. http://dx.doi.org/10.1177/1354066111409771

[9] Pearce II, J.A. and Robinson, R.B. (2000) Cultivating Guanxi as a Foreign Investor Strategy. Business Horizons, 31-38.

[10] Bell, D.A. (2010) Recondiling Socialism and Confucianism? Revibing Tradition in China. Dissent, 57, 91-99. http://dx.doi.org/10.1353/dss.0.0114

[11] Wong, M.L. (2007) Guanxi Ensures the Service Quality. The International Journal of Diversity in Organizations, Communities and Nations.

[12] Wong, M.L. (2007) Guanxi and Its Role in Business: an Empirical Investigation in Insurance Industry. Chinese Management Studies, 1, 257-276. http://dx.doi.org/10.1108/17506140710828532

[13] Wong, M.L. (2010) Guanxi Management in Lean Production System-An Empirical Study of Taiwan-Japanese Firms. Journal of American Journal of Economics and Sociology (SSCI).

[14] Wong, M.L. (2010) Guanxi Management as Complex Adaptive Systems: A Case Study of Taiwanese ODI in China. Journal of Business Ethics (SSCI), 91, 419-432. http://dx.doi.org/10.1007/s10551-009-0093-1

[15] Doctoroff, T. (2011) A Continuum of Twelve Quintessential Chinese Behavioral Characteristics. Symposium: Consumer Culture in Global Perspective, 48, 123-130.

[16] Ruiqi, Z. and Adrian, P. (2009) Using Servqual to Measure the Service Quality of Travel Agents in Guangzhou, South China. Journal of Services Research, 9, 87.

[17] Parasuraman, A., Zeithaml V.A. and Arvind, M. (2005) E-S-QUAL: A Multiple-Item Scale for Assessing Electronic Service Quality. Journal of Service Research, 7, 1-21

[18] Magal, S.R. (1991) A Model for Evaluating Information Center Success. MIS Quarterly, 8, 91-106.

[19] Landrum, H. and Prybutok, V.R. (2004) A Service Quality and Success Model for the Information Service Industry. European Journal of Operational Research, 156, 628-642. http://dx.doi.org/10.1016/S0377-2217(03)00125-5 